\title{
Prenatal Exposure to Endocrine-Disrupting Chemicals and Asthma and Allergic Diseases
}

\author{
Casas $\mathrm{M}^{1,2,3}$, Gascon $\mathrm{M}^{1,2,3}$ \\ 'ISGlobal, Barcelona, Spain \\ ${ }^{2}$ Pompeu Fabra University, Barcelona, Spain \\ ${ }^{3}$ Spanish Consortium for Research on Epidemiology and Public Health (CIBERESP), Madrid, Spain
}

J Investig Allergol Clin Immunol 2020; Vol. 30(4): 215-228

doi: 10.18176/jiaci.0580

\begin{abstract}
Endocrine-disrupting chemicals (EDCS) interfere with endogenous hormones and are present in many consumer products. In addition, they affect the development and functions of the immune system. The prenatal period is critical, because exposure to EDCs can induce irreversible changes in the immune system and increase susceptibility to asthma and allergies later in life. Nonpersistent EDCs are of most concern owing to their high annual production and potential toxicity. In this review, we summarize the literature on the effects of prenatal exposure to nonpersistent EDCs — phthalates and phenols — on asthma and allergic diseases, describe the underlying biological mechanisms, and make recommendations. Between 2011 and 2020, a total of 19 prospective studies were published. Most of these were focused on phthalates and bisphenol A and few on other bisphenols, parabens, triclosan, and benzophenone-3. Evidence remains insufficient owing to differences in chemical use between countries, sociodemographic characteristics of the study populations, misclassification of exposure due to the high within-subject variability, and heterogeneity in the definition of health outcomes. EDCs can alter airway cell differentiation and gut microbiota, shift the immune response towards $T_{H} 2$, alter expression of $T$ regulatory cells and $T_{H} 17$, and weaken innate immunity. In order to better understand the burden of EDCs on the respiratory and immune systems, we require thoughtfully designed studies to assess exposure, appropriately characterize asthma and allergic phenotypes, and evaluate biological mechanisms and EDC mixtures. Research will help to implement public health policies that reduce exposure to EDCs in the community, particularly in pregnant women.
\end{abstract}

Key words: Endocrine disruptors. Pregnancy. Asthma. Eczema. Food allergy. Immune system.

\section{Resumen}

Los disruptores endocrinos (DEs), sustancias químicas que pueden interferir con las hormonas endógenas y que están presentes en muchos productos de consumo, pueden afectar el desarrollo y función del sistema inmune. El período prenatal es crítico porque su exposición puede inducir cambios irreversibles en el sistema inmunitario y aumentar la susceptibilidad al asma y alergias. Los DEs de mayor preocupación son los no persistentes por su alta producción y potencial toxicidad. En esta revisión, resumimos la literatura sobre los efectos de la exposición prenatal a DEs no persistentes (ftalatos y fenoles) sobre el asma y las alergias, describimos los mecanismos biológicos y desarrollamos recomendaciones. Entre 2011 y 2020, se publicaron un total de 19 estudios prospectivos. La mayoría se centraron en ftalatos y bisfenol A y pocos en otros bisfenoles, parabenos, triclosán y benzofenona-3. En general, la evidencia aún es insuficiente, probablemente debido a diferencias en el uso de químicos y las características sociodemográficas entre países, la clasificación errónea de la exposición y la heterogeneidad en la definición de los fenotipos. Los DEs pueden alterar la diferenciación celular de las vías respiratorias, cambiar la respuesta inmune hacia Th2, alterar la expresión de las células T reguladoras y Th17 y alterar la microbiota intestinal. Se necesitan estudios con buena medida de exposición y caracterización de los fenotipos y que consideren mecanismos biológicos y mezclas de DEs. Esta investigación contribuirá a la implementación de políticas de salud pública para reducir la exposición a los DEs en la comunidad, particularmente en mujeres embarazadas.

Palabras clave: Disruptores endocrinos. Embarazo. Asma. Eczema. Alergia alimentaria. Sistema inmune. 


\section{Introduction}

The prevalence of asthma and allergic diseases has increased dramatically in recent decades, especially in children [1]. It is estimated that, on average, $12 \%$ of children around the world are affected by asthma, $9 \%$ by allergic rhinitis, and $22 \%$ by eczema [2-4]. These numbers vary considerably between regions, with the highest prevalence recorded in Northern European countries [2]. Food allergies are also common, affecting up to $10 \%$ of children $[3,5,6]$. In a recent population-based cohort of 1301 European children from the UK, France, Greece, Spain, Norway, and Lithuania (20132016, mean age: 8 years) [7], we reported a similar prevalence for asthma (12\%), eczema (21\%), and food allergies (10\%), but a higher prevalence for allergic rhinitis (25\%) (manuscript in preparation). Of interest, these symptoms often co-occur in the same individual (multimorbidity), more commonly than expected by chance [4].

The reasons for the increased prevalence of asthma and allergic diseases have not been well established. Although these diseases have a genetic component, the rapid increase cannot only be due to changes in the underlying genetic susceptibility of the population [8]. Changes in lifestyle and in the environment are believed to play a key role in allergic diseases, particularly during early stages of development. Indeed, the fetal period is a critical window for the development of the immune system owing to the immaturity of fetal organ systems and undeveloped detoxification processes. Exposure to a harmful environment during this period can induce irreversible changes in the immune system and increase susceptibility to asthma and allergic diseases later in life [9]. This observation is consistent with the Developmental Origins of Health and Disease (DOHaD) approach [10], which states that early-life factors may have a long-term impact on disease in adulthood.

Many early-life lifestyle and environmental factors have been reported to contribute to the development of respiratory and allergic diseases, including maternal atopy/asthma, inadequate diet during pregnancy, tobacco smoke, prepregnancy obesity, psychological distress, low birth weight, rapid infant growth, and viral respiratory infections [11-13]. Among environmental exposures, air pollution caused by traffic has been widely studied, and it is estimated that 4 million new cases of pediatric asthma are attributable to nitrogen dioxide pollution annually $[14,15]$. More recently, concern has been growing over the impact of environmental chemicals on onset of asthma and allergic diseases. Endocrine-disrupting chemicals (EDCs) in particular have gained attention owing to their capacity to affect the development and function of the immune system [16].

\section{Endocrine-Disrupting Chemicals}

EDCs are natural or synthetic chemicals that can interfere with the synthesis, secretion, binding, transport, and metabolism of endogenous hormones involved in regulating developmental processes [17]. Synthetic EDCs are produced in large quantities worldwide and used in many consumer goods. Millions of tons of synthetic chemicals are produced every year $(>300$ million tons consumed in Europe in 2018 [18]) and many are suspected or proven EDCs. Reported figures vary from 86 included in the REACH Regulation of the European Chemicals Agency (ECHA) [19] to 1482 included in The Endocrine Disruption Exchange (TEDX) list [20]. However, the exact number of EDCs in marketed products is unknown, as there are no common criteria for labelling a chemical as an EDC [21,22]. EDCs include historical persistent organic pollutants (eg, dioxins), polychlorinated biphenyls (PCBs), and pesticides (eg, dichlorodiphenyltrichloroethane [DDT], which was banned), as well as emerging persistent and nonpersistent compounds such as per- and polyfluoroalkyl substances (PFASs), phenols (eg, bisphenol A [BPA], parabens), and phthalates. Emerging compounds are particularly concerning owing to their high annual production and potential toxicity.

Human populations are continuously exposed to EDCs through food (pesticides), food packaging (phenols, phthalates), cosmetics (parabens, phthalates), dust inhalation (phthalates), and consumer goods (phthalates in paints, PFASs in nonstick cookware). Human exposure to EDCs is widespread, as observed in many human biomonitoring studies [23-25]. Of concern, exposure to these chemicals is considerable in pregnant women and children, with most compounds being detected in more than $90 \%$ of body fluids [25-27]. Infants and young children generally present higher levels than adults because they lack specific detoxification pathways and are exposed via other channels, such as breastfeeding and crawling. Most compounds can also cross the placental barrier. Although some European countries (eg, France) have started to ban the marketing of certain EDCs, such as BPA, new compounds with endocrinedisrupting capacity are continuously being produced, and their potential toxicity is unknown. Indeed, the 7th EU Environment Action Programme, which is committed to the development of a nontoxic environment by 2020 [28], was developed in response to emerging issues related to the growing presence of chemicals in everyday life. In addition, the current EU Commission has presented the "The European Green Deal", which aims for a nontoxic environment by 2050.

Given the activity of EDCs, exposure in vulnerable time periods (ie, prenatal life) can induce changes in organ and tissue development, with adverse effects occurring in the short and long terms, such as obesity and metabolic disorders, male and female reproductive disorders, reproductive cancers, thyroid disorders, neurodevelopmental delay, and IQ loss [21]. Exposure to EDCs has been estimated to cost the EU $\$ 163$ billion in disease and dysfunction across the course of a lifetime [29]. EDCs can also disrupt the development and functioning of the immune and respiratory systems. For persistent EDCs, the evidence of their effects on respiratory health is moderate [30], whereas for nonpersistent EDCs it is inadequate [31]. In this review, we summarize current knowledge about the effects of prenatal exposure to nonpersistent EDCs, namely, phthalates and phenols (bisphenols, parabens, triclosan, and benzophenone-3), on asthma and allergic diseases, and discuss potential biological mechanisms. We also develop recommendations for future studies. 


\section{Phthalates}

Phthalates are a group of phthalic acid diester compounds with straight or branched chain alcohols that are generally used as plasticizers to add flexibility to plastic consumer products. Around 6-8 million tons of phthalates are consumed every year [32]. Phthalates are divided into long-chain phthalates, such as di-2-ethylhexyl (DEHP), butylbenzyl (BBzP), and di-isononyl (DiNP) phthalates, and short-chain phthalates such as di-ethyl (DEP) and di-n-butyl (DnBP) phthalates. Long-chain phthalates are widely used in polyvinyl chloride (PVC) applications and are present in building materials, food containers, and many other consumer products. Short-chain phthalates are further used in non-PVC products including adhesives and personal care products. Phthalates are not chemically bound to other substances and can therefore be easily released into the air or leached from plastic, leading to food and environmental contamination [33]. Whereas food is considered to be the major source of exposure for long-chain phthalates, personal care products and indoor air may be an important source of exposure for short-chain phthalates. In 1999, the EU banned the use of 3 phthalates (ie, DEHP, dibutyl phthalate $[\mathrm{DBP}]$, and benzyl butyl phthalate $[\mathrm{BBP}]$ ) in the manufacture of toys and childcare articles. In 2011, these 3 phthalates and diisobutyl phthalate (DiBP) were added to the $\mathrm{REACH}$ candidate list owing to their suspected reproductive toxicity [34].

\subsection{Mechanisms}

Phthalates have been reported to have estrogenic, antiestrogenic, and antiandrogenic effects depending on the congener and metabolite analyzed. For instance, DEHP seems to have estrogenic activity, whereas monobenzyl phthalate (MBzP), a metabolite of BBzP, seems to have antiestrogenic activity. Further studies are needed to clarify the various activities of phthalate compounds $[35,36]$. Because of their potential endocrine-disrupting activity, some phthalates (eg, DEHP, DiNP, diisodecyl phthalate [DiDP]) have been reported to bind the peroxisome proliferator-activated receptor $\gamma(\mathrm{PPAR} \gamma)[37,38]$. In the case of DEHP, this interaction with PPAR $\gamma$ alters airway cell differentiation and surfactant protein production in the lungs, thus explaining the potential association between DEHP and asthma [39]. It is not clear whether phthalates increase inflammatory responses [40]. However, what seems to be more consistent, according to animal and in vitro studies, is that several phthalates can have adjuvant effects on type 2 helper $\mathrm{T}$ cell $\left(\mathrm{T}_{\mathrm{H}} 2\right)$ differentiation and influence antibody response, thus affecting the adaptive immune system $[40,41]$. Other studies have also reported alterations of the innate immune system, such as increased production of tumor necrosis factor $\alpha(\mathrm{TNF}-\alpha)$ by macrophages, and reduced capacity for migration of these cells [16].

\subsection{Current Evidence From Birth Cohort Studies}

In the first epidemiological studies on phthalates and respiratory health, exposure was assessed by measuring home dust phthalate levels or by counting the number of rooms with PVC flooring [42]. We only took into consideration studies that assessed exposure to phthalates using biomarkers; a total of 13 studies have been published to date (Table). In 2017, Li et al [42] performed a systematic review and meta-analysis including 5 [43-47] of these 13 studies, and observed that prenatal exposure to $\mathrm{MBzP}$ was associated with an increased risk of asthma. Since this systematic review, a further 8 studies have been published [48-55]. In 2 cohorts, in utero exposure to long-chain phthalates and DiDP and DiNP metabolites was associated with an increased risk of bronchiolitis/bronchitis, wheezing, and asthma $[49,53]$. These findings are relevant, because DiDP and DiNP are increasingly used as DEHP substitutes and are the most commonly used plasticizers in Western Europe [56,57]. Recently, in another cohort, exposure to $\mathrm{MBzP}$ from pregnancy until 9 years of age was associated with an increased risk of wheezing and asthma in children; however, the study did not separately assess the effects of prenatal and postnatal exposures [54]. In contrast, a decreased risk of wheezing was associated with prenatal exposure to metabolites of DEP and DnBP [51]. Regarding allergic disorders, exposure to metabolites of DiNP and DiBP was associated with an increased risk of eczema [50], and, among sensitized boys, exposure to metabolites of DiBP and DBP increased the risk of ever eczema [50]. Food allergies have been assessed in only 1 cohort, in which the authors observed that prenatal exposure to $\mathrm{MBzP}$ increased the risk of food allergy [55]. The same cohort also found an association between DEHP metabolites and increased risk of food allergies and lower risk of atopic dermatitis; however, no difference was made between prenatal and postnatal exposures in the models [54]. Finally, 2 studies explored the link between phthalates and immune biomarkers: one study found an association between a DnBP metabolite and higher $\mathrm{T}_{\mathrm{H}} 2$ percentage in children younger than 5 years [52], whereas the other did not find any association with immune markers measured in cord blood [48].

\section{Phenols}

\subsection{Bisphenols}

Bisphenols are used in the manufacture of plastic polymers, such as polycarbonate plastics and epoxy resins. Diet represents the main source of exposure. The most widely known, produced, and used bisphenol is BPA, whose global production in 2015 was estimated at 5.4 million tons [58]. BPA was first reported to be an EDC in the late 1930s and was recently formally identified as an EDC by the European Chemicals Agency (ECHA). Owing to concern over effects on neurodevelopment and other toxic effects, the EU banned BPA in baby bottles in 2011 [59], and its use has recently been restricted in thermal paper [60]. Consequently, chemical companies have started to generate other molecules to replace BPA, such as bisphenol S (BPS) and bisphenol F (BPF). However, these molecules have similar properties to BPA and are suspected of having similar toxicity [61].

\subsubsection{Mechanisms}

BPA is estrogenic and binds to estrogen receptors $\alpha$ and $\beta$, with approximately 10 -fold higher affinity for the $\beta$ receptor 


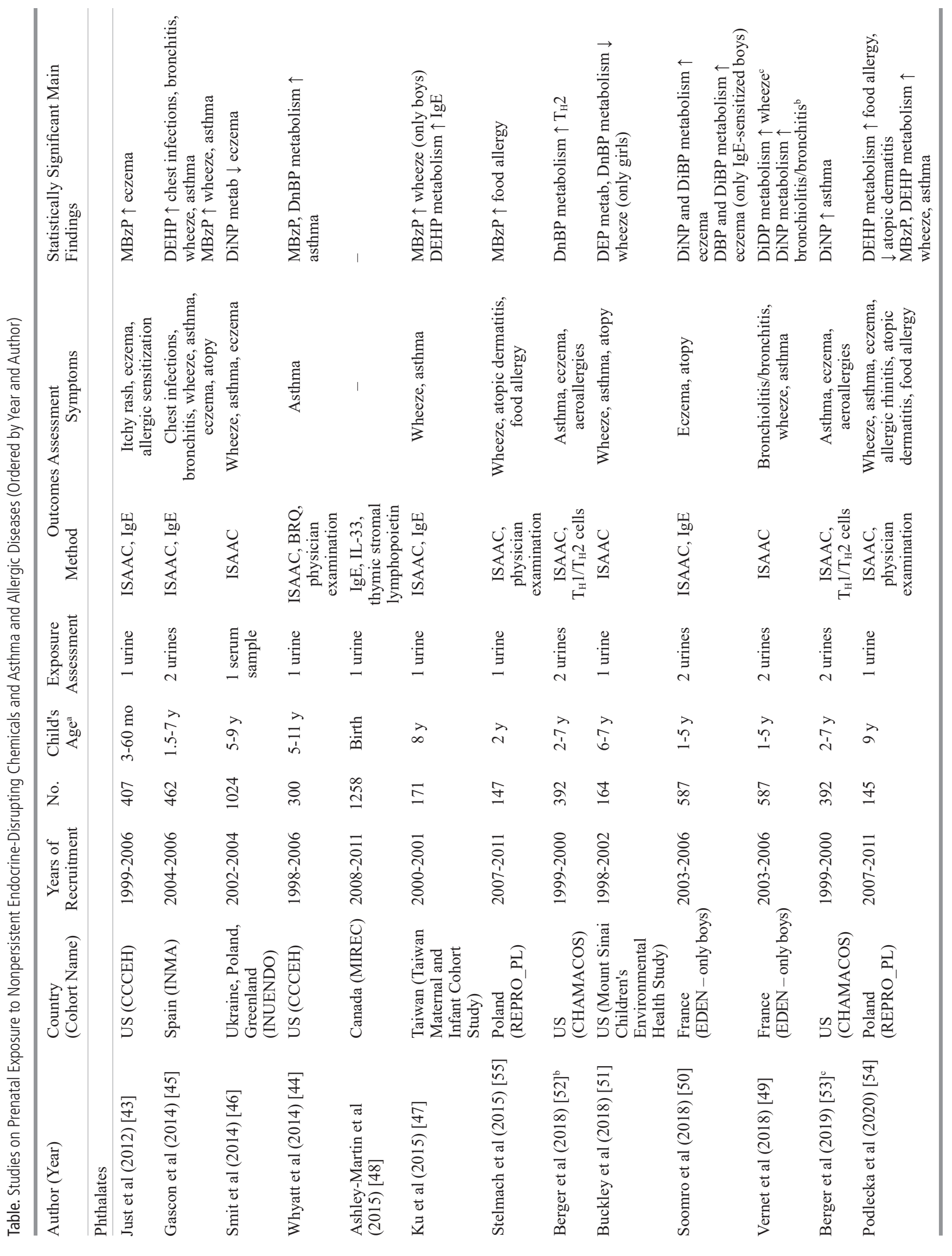




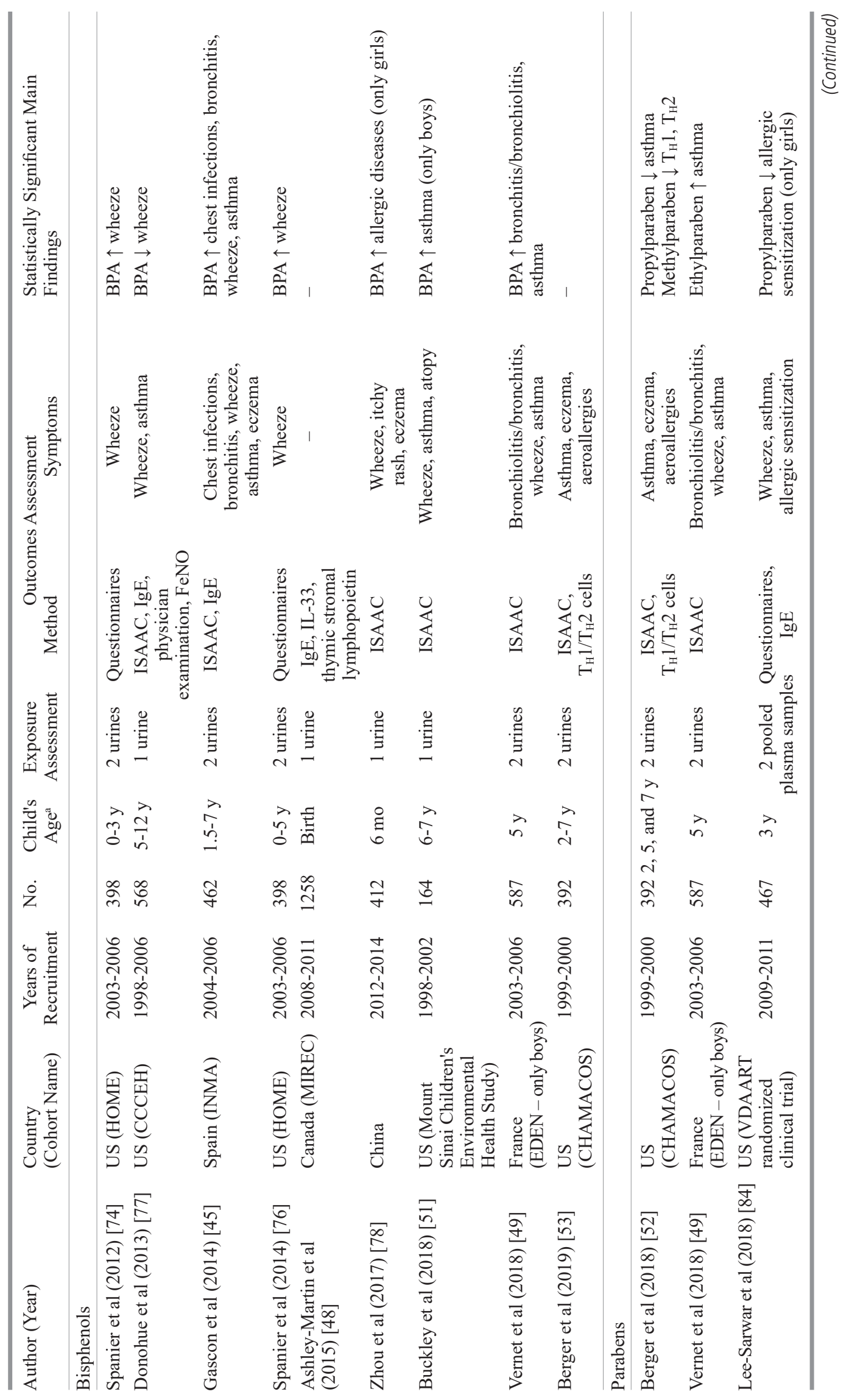




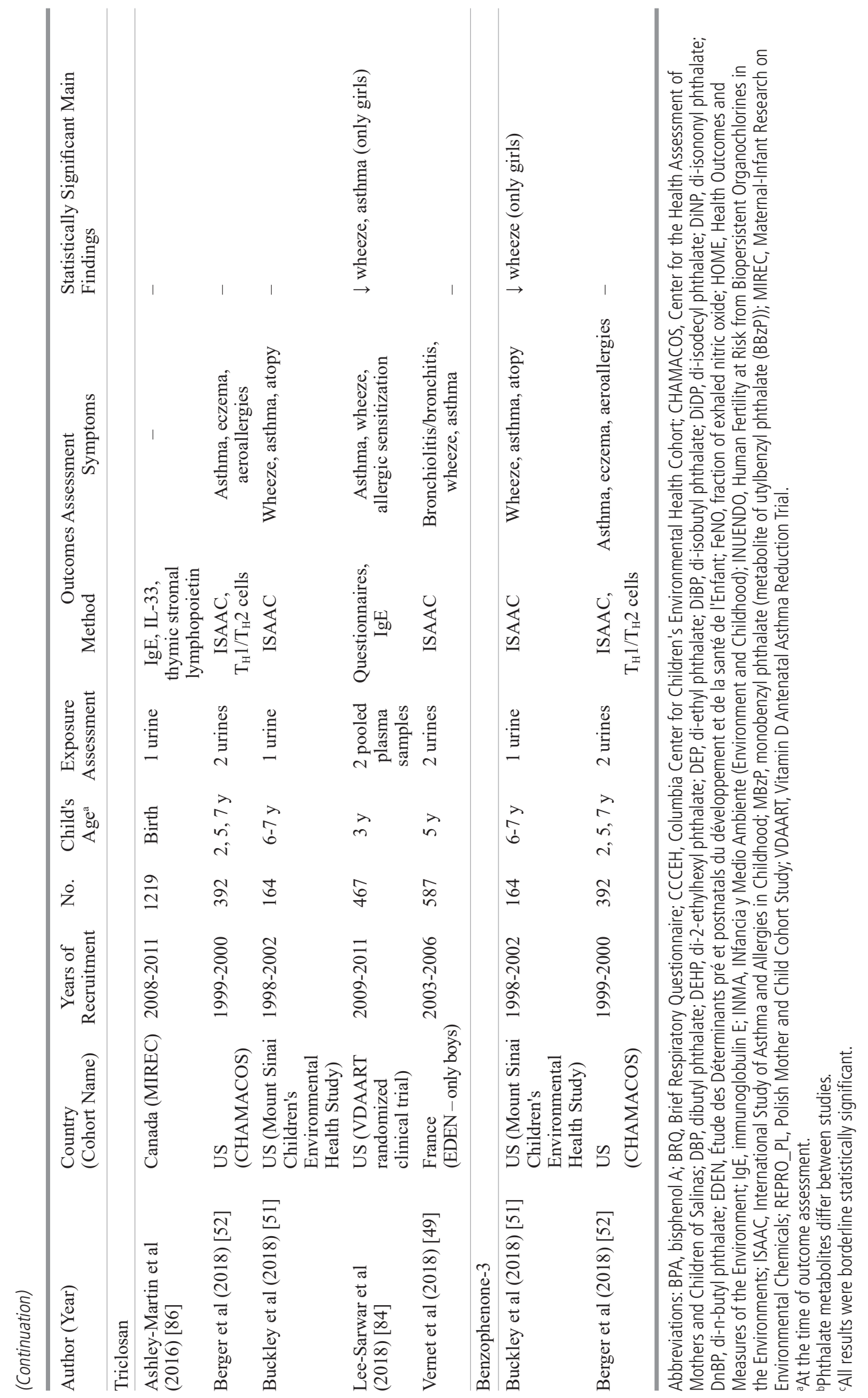


[62]. It also binds to androgen and progesterone receptors, PPAR, and the aryl hydrocarbon receptor, a ligand-dependent transcription factor present in almost every tissue $[63,64]$. In fact, some studies have observed that BPA can stimulate cellular responses at concentrations below the levels where it is expected to bind to the classic nuclear ERs $[65,66]$. It also binds to the thyroid hormone receptor, inhibiting the transcriptional activity stimulated by triiodothyronine (T3) [64]. This endocrine-disrupting activity explains the immunomodulatory properties of BPA observed in animal and in vitro models $[63,64,67,68]$, as in humans [69]. The immune effects observed in relation to BPA exposure include $T_{H} 1 / T_{H} 2$ cell shifts, reduction in $\mathrm{T}$ regulatory (Treg) cells (which are important in controlling proinflammatory reactions), $\mathrm{T}_{\mathrm{H}} 17$ alterations $\left(\mathrm{T}_{\mathrm{H}} 17\right.$ are involved in the pathogenesis of various autoimmune and inflammatory diseases), reduced innate immunity, increased B-cell count and activity, and increased oxidative stress and expression of immunity-related genes $[63,64,70]$. Altered airway cells in rhesus macaques have also been reported [71].

\subsubsection{Current evidence from birth cohort studies}

Studies conducted to date on the effects of exposure to bisphenols during fetal life on asthma and allergic diseases have focused on BPA (Table). To our knowledge, only 1 study has assessed the influence of BPS and BPF on asthma and hay fever using data from 3500 persons aged 12 years or older participating in the National Health and Nutrition Examination Survey (NHANES) for 2013-2016 [72]. In this cross-sectional study, BPS and BPF were associated with increased odds of current asthma [72]. Regarding the effects of in utero exposure to BPA, a systematic review of cohort studies conducted in 2016 [73] identified 3 studies showing an association between prenatal exposure to BPA and increased risk of childhood wheeze, chest infections, bronchitis, and asthma [74-76], whereas 1 study reported a decreased risk of wheeze [77]. This systematic review was followed by a further 5 studies $[48,49,51,53,78]$. Three reported an increased risk of asthma, lower respiratory tract infections, and allergic diseases (ie, itchy rash and eczema) associated with prenatal exposure to BPA [49,51,78], whereas 2 reported no association with asthma, aeroallergies, eczema, or immune markers such as immunoglobulins, interleukins, and $\mathrm{T}_{\mathrm{H}} 1$ and $\mathrm{T}_{\mathrm{H}} 2$ cytokineproducing cells $[48,53]$. Sex-specific effects were identified in only 2 studies with inconsistent results: one reported a higher risk of allergic diseases among girls [78], and the other reported a higher risk of asthma among boys [51].

\subsection{Parabens}

Parabens are alkyl esters of p-hydroxybenzoic acid with antifungal and antibacterial properties. They are frequently used as preservatives in cosmetic products, toiletries, foods, and pharmaceuticals. The most common are methyl-, ethyl-, propyl-, and butylparaben, which are used alone or in the form of a mixture to increase their efficacy. Parabens enter the human body mainly through ingestion or skin absorption, although they are also present in dust and indoor air. Their production has increased rapidly in recent decades. In the early 2000 s, it is estimated that parabens were present in more than $90 \%$ of cosmetic products [79]. Given their cytotoxicity and endocrinedisrupting properties, the EU restricted the use of parabens as preservatives in cosmetic products, with limits of $0.4 \%$ for a single ester and $0.8 \%$ for a mixture of parabens [80].

\subsubsection{Mechanisms}

The antimicrobial activity of these compounds could be altering microbiota in the gut (or other body sites) and shifting the $\mathrm{CD}^{+}$response towards a $\mathrm{T}_{\mathrm{H}} 2$ response, which is associated with allergy, eczema, and other diseases [81]. In fact, a study conducted in 2012 in almost 900 schoolchildren in the USA observed that concentrations of parabens were associated with increased levels of immunoglobulin E (IgE) [82]. However, appropriate data on prenatal exposure are lacking. In addition, parabens of long alkyl chains (eg, decylparaben) induce the release of histamine [16]. For instance, heptylparaben, another long-alkyl-chain paraben used as a food additive, has been reported to induce a strong allergic reaction on animal skin [83]. Other research has shown genotoxic and cytotoxic effects of parabens on human lymphocytes in vitro and their capacity to suppress immune response [83].

\subsubsection{Current evidence from birth cohort studies}

A total of 3 cohort studies, all published in 2018, evaluated the effect of prenatal exposure to parabens and asthma and allergic outcomes in offspring (Table). Two observed a decreased risk of asthma [52] and allergic sensitization associated with exposure to propylparaben (only in girls in the second study) [84], and a lower percentage of $\mathrm{T}_{\mathrm{H}} 1$ and $\mathrm{T}_{\mathrm{H}} 2$ cells associated with exposure to methylparaben [52]. On the contrary, one study, which only included boys, observed an increased risk of asthma following exposure to ethylparaben [49].

\subsection{Triclosan}

Triclosan is widely used as an antimicrobial agent and preservative in cosmetics, personal care products (eg, toothpaste), detergents, and other household cleaning products. Ingestion and dermal absorption are the main routes of exposure. Of interest, the chemical structure of triclosan is similar to that of PCBs, BPA, dioxins, and thyroid hormones [85]. In 2002, the worldwide production of triclosan exceeded 1500 tons per year [85]. Although the use of triclosan is not highly regulated, in light of mounting evidence on potential health effects, some companies have decided to remove triclosan from their products.

\subsubsection{Mechanisms}

As with parabens, the antimicrobial activity of triclosan may alter human microbiota and shift the immune response towards $\mathrm{T}_{\mathrm{H}} 2$ [81]. Savage et al [82] also showed higher $\operatorname{IgE}$ levels in a population of school-aged children who were increasingly exposed to triclosan. However, as commented on below, relevant data on prenatal exposure are lacking. In addition, triclosan can inhibit the lytic function of naturalkiller cells (NK) and mast cell degranulation and affect autophagy (an intracellular process that delivers the cargo, 
including pathogens, to lysosomes for degradation) of specific macrophages (RAW264.7 cells) [16].

\subsubsection{Current evidence from birth cohort studies}

To date, 5 cohort studies have assessed whether fetal exposure to triclosan increases the risk of asthma and allergies in childhood (Table). Four did not observe any association between prenatal exposure to triclosan and asthma, wheezing, eczema, atopy, or immune biomarkers $[49,51,52,86]$. The fourth study reported a decreased risk of asthma and wheeze, but only in girls [84].

\subsection{Benzophenone-3}

Benzophenone-3, or oxybenzone, is a phenolic compound that is frequently used as an ultraviolet filter in sunscreen and as a fragrance enhancer in personal care products. Benzophenone- 3 is one of the most widely used benzophenones for UV filters. Other benzophenones include benzophenone-1, which is used as a UV stabilizer in plastic surface coatings on food packages. Dermal and oral routes are the main sources of exposure. Benzophenone-3 is lipophilic and can accumulate in human and animal tissues [87]. It is estimated that 10000 tons of UV filters are produced annually for the global market [87]. In 2017, the EU regulated the use of benzophenone-3 as a UV filter in up to $6 \%$ of cosmetic sunscreens and in up to $0.5 \%$ of cosmetic products [88].

\subsubsection{Mechanisms}

There is very limited information on the potential mechanisms by which benzophenone- 3 increases the risk of allergic diseases and asthma. As with the previous compounds analyzed, a recent review suggests that it could stimulate the differentiation of $\mathrm{T}$ cells towards a $\mathrm{T}_{\mathrm{H}} 2$ response [16]. However, further animal and in vitro studies are needed to better understand the potential mechanisms involved.

\subsubsection{Current evidence from birth cohort studies}

Only 2 studies have evaluated the potential effects of benzophenone- 3 on asthma and allergic diseases in childhood (Table). One showed a lower risk of wheezing among girls [51], whereas the other did not observe any associations [52].

\section{State of the Art and Future Research}

In this review, we present updated evidence of the effects of exposure to phthalates and phenols during pregnancy on the development of asthma and allergic diseases in childhood. Although the number of studies on phthalates and BPA is quite extensive, they are still subject to inconsistencies. For triclosan, parabens, and benzophenone- 3 in particular, the number of studies is very limited. Consequently, the potential effects of EDCs on immune and respiratory health are not taken into consideration when estimating their burden [29]. Indeed, their burden is calculated only by assessing the effects on obesity, diabetes, reproductive disorders, IQ loss, and behavioral problems [29]. Of relevance, although the EU recently funded 12 projects to improve the identification of EDCs [89] (call
SC1-BHC-27-2018), none consider the effects on respiratory or immune health for their identification. Given the scarcity of studies and their inconsistent results, further work is needed to elucidate the role of EDCs in asthma and allergies.

Discrepancies across studies may reflect differences in chemical use between countries and/or in sociodemographic characteristics of the populations. The fact that most studies have small samples (fewer than 600) may hinder the identification of most vulnerable subgroups (eg, according to sex, sociodemographic characteristics, preterm births). Inconsistencies between studies may also be due to the nonmonotonic dose-response curves associated with exposure to EDCs (ie, low doses can have more potent effects than higher doses) [90]. Combining data from different birth cohorts can lead to more conclusive results, as well as to a more robust analysis, including effect modifiers and adequate modelling of the exposure-response relationship [91,92]. In most cohorts, pregnant women were recruited more than a decade ago (Table), and newer EDCs could not be detected at that time. For example, in the INMA cohort [45], where pregnant women were recruited between 2004 and 2006, BPS was not detected in most of the maternal urine samples (unpublished results). Although the structure and mechanisms of action of new substitutes are similar to those of the initial ones and we therefore expect that they would have similar health effects, their potential toxicity can only be assessed in recently established population-based studies. Finally, it is important to consider that we have not reviewed the literature on exposure to currently used pesticides (eg, organophosphate pesticides), glycol ethers, and polycyclic aromatic hydrocarbons (PAHs), which can also have an endocrine-disrupting effect and thus lead to asthma and allergies.

\subsection{Improving Exposure Assessment}

Because we expect effect sizes associated with exposure to EDCs to be small, a reliable exposure assessment is needed to assess the effects of these compounds on respiratory and immune health. All cohort studies but 2 determined the levels of phthalates and phenols in spot urine samples collected during pregnancy (Table). Two cohorts $[46,84]$ used maternal serum or plasma to assess exposure to these nonpersistent EDCs. On ingestion, phthalates and phenols are metabolized rapidly and excreted in urine after a few hours or days. A low proportion are retained in blood, and circulating levels are usually lower than urinary levels; hence, assessment of urinary levels is the preferred option [93]. However, given that EDCs are excreted quickly in urine, concentrations determined in a spot urine sample only reflect exposure for a short period of time. Substantial measurement error, such as that occurring when a limited number of urine samples are taken to characterize longterm exposure, can result in attenuated associations in analyses linking an exposure with a health outcome if the error in the assessment is random and consequently not associated with the outcome (nondifferential) [94]. It is estimated that in the case of compounds with very high within-subject variability, such as BPA, attenuation bias (underestimation of the effects) can reach $80 \%$ [95]. Recently, new sampling strategies have been postulated to limit misclassification of exposure by pooling several urine samples per subject $[95,96]$. This 
pooling approach is logistically feasible and does not increase analytical costs since only 1 urine pool is eventually analyzed [96]. We demonstrated that this is a valid approach for most phthalates and phenols, but not for other substances such as organophosphate pesticides, to which we are intermittently exposed (in this case, more than 40 urine samples are required during pregnancy [96]). Levels of the most variable compounds can be alternatively determined in hair samples with much lower within-subject variability than urine concentrations [97], as this approach reflects long-term exposure. Another alternative, is the use of personal silicone wristbands as passive samplers [98]; these also provide information on long-term exposure and correlate well with metabolites in urine for some compounds, such as PAHs [99].

\subsection{Improving Assessment of Asthma and Allergic Phenotypes}

Proper characterization of asthma and allergy phenotypes is required to adequately identify underlying environmental causes. Almost all the studies reviewed collected information on asthma and allergic symptoms using the International Study of Asthma and Allergies in Childhood (ISAAC) questionnaire administered to the mothers (Table). The use of standardized questionnaires enables results to be compared across studies, although they can be subject to under- or over-reporting of the symptoms, which may lead to attenuation or overestimation of the results. This can be solved by considering information on symptoms collected at multiple time points during childhood, as was the approach in some studies $[44,45]$, or by a physical examination of children with respiratory symptoms, as was the case in the Columbia Center for Children's Environmental Health Cohort (CCCEH) [77]. However, we recognize that this is not always possible. Allergy can be better diagnosed by performing a skin prick test, measurement of fractional exhaled nitric oxide (FeNO), or measurement of IgE levels, as in some cohorts (Table). Given the heterogeneity of asthma and allergic phenotypes, there is no uniform set of diagnostic criteria, and definitions vary according to the study. In the CCCEH cohort, for example, allergists and pediatric pulmonologists defined asthma based on current asthma-related symptoms and medication, the postbronchodilator test result, and a history of asthma on previous questionnaires [77], whereas in INMA [45] we defined asthma following the MeDALL recommendations [100], which take into account questions on physician-based diagnosis, asthma treatment, and wheezing symptoms. Nevertheless, we should also consider that although a physician-based diagnosis provides more reliable information than parent-reported respiratory symptoms, variations in the prevalence of asthma and allergic diseases between countries may reflect differences in diagnostic criteria (readily diagnosed in some countries while unrecognized in others) [58]. Future studies assessing the effects of prenatal exposure to EDCs on asthma and allergy should include a better characterization of asthma and allergic phenotypes by considering alternative tests and the course of respiratory symptoms [101], assessing food allergy (since only 1 study has assessed it), and following up children at later ages (children were younger than 11 years in all studies) to elucidate whether the effects of early-life exposure to EDCs persist into adolescence and adulthood. Moreover, we recommend taking multimorbidity into consideration, since it has been shown that asthma and allergic diseases co-occur more often than expected by chance [4] and that they may coexist with other diseases that have also been associated with EDCs [21], such as other respiratory problems (eg, impaired lung function) [102], cardiovascular and metabolic diseases [103], and some mental health disorders (eg, attention-deficit/ hyperactivity disorder) [104].

\subsection{Assessing Mixtures of EDCs}

Humans are exposed to multiple EDCs simultaneously, and it is important to understand how these multiple compounds interact and which EDCs are the most toxic in relation to asthma and allergy. Most of the studies included in this review assessed a single EDC at a time. Some studies adjusted the models for another EDC (eg, [44,45]), while Smit et al [46] considered many EDCs simultaneously (phthalates, perfluoroalkyl compounds, DDT metabolites, and PCBs). In order to address the high correlation between these chemicals, the authors applied a dimension reduction method-principal component analysis - to transform a number of correlated variables into a smaller number of uncorrelated principal components [105]. However, exposure to multiple EDCs can result in synergistic, antagonistic, or cumulative effects (for compounds acting via similar pathways) $[106,107]$. There is substantial toxicological evidence that mixtures are often more toxic than the individual compounds [106,108]. For example, using data from the CCCEH cohort, Whyatt et al [109] tested the interaction between maternal phthalate levels and child BPA levels and observed that the association between BPA and respiratory outcomes was present only among those children whose mothers had high levels of MBzP during pregnancy. Studying the health effects of exposure to combinations of EDCs requires an assessment of the potential for interaction between copollutants and for confounding between exposures, as well as a careful consideration of the biological mechanisms and modes of action involved [17,106,110]. New statistical tools to estimate the effect of multipollutant mixtures are being developed, particularly within the framework of exposome research $[105,111]$. Although research on exposure to multiple EDCs has just started, international bodies such as the World Health Organization already recognized the need to include mixtures in the assessment of chemical risk and for purposes of regulation [108,112].

\subsection{Exploring the Biological Mechanisms}

Understanding the biological pathways through which EDCs can increase the risk of asthma and allergies is key to establishing a causal inference. Studies performed to date show that EDCs can affect the development, functions, and lifespan of immune cells [16]. EDCs can also increase the risk of asthma and allergies through epigenetic changes (eg, alterations of DNA methylation) $[113,114]$. However, epigenetic studies require large samples to achieve optimal statistical power and various populations to replicate the findings in order to reduce false-positive results. The international Pregnancy And Childhood Epigenetics (PACE) Consortium, which includes 39 studies with DNA methylation data, provides an excellent opportunity to address this issue [115]. Another potential 
mechanism that is just starting to be studied is changes in gut microbiota; the gut microbiome and the immune system develop in parallel and with strong crosstalk throughout life. Some EDCs have been reported to worsen gut dysbiosis in animal models, and this is thought to be associated with immune alterations [116-118]. It would be particularly interesting to study the effect of compounds that are specifically designed to exercise an antimicrobial effect (eg, triclosan and parabens) [81].

\section{Conclusion}

Exposure to EDCs during vulnerable periods can disrupt the development and functioning of the immune and respiratory systems and increase the risk of asthma and allergic diseases in children. In this review, we summarized current evidence for the effects of prenatal exposure to phthalates and phenols on respiratory outcomes and allergies and concluded that the evidence is still insufficient. In order to better understand the burden of EDCs on the respiratory and immune systems, we require thoughtfully designed studies to assess exposure, appropriately characterize asthma and allergic phenotypes, and evaluate biological mechanisms and EDC mixtures. Research will help us to implement public health policies to reduce exposure to EDCs in the community, particularly in pregnant women. EDCs are not covered efficiently in current EU regulations on chemicals (registration, evaluation, authorization, and restriction), additives, and cosmetics [21]. Given the widespread exposure to EDCs and their potential toxicity, the application of the precautionary principle (ie, act to address potential harmful issues without complete scientific certainty) would be the best approach, particularly if we are to protect the most vulnerable groups such as pregnant women and children. EU chemical legislation, which is currently dominated by a substance-by-substance approach, should move towards avoiding entire chemical classes (ie, specific hazard regulations) instead of individual compounds.

\section{Funding}

Maribel Casas and Mireia Gascon hold a Miguel Servet fellowship (CP16/00128 and CP19/00183, respectively) funded by Instituto de Salud Carlos III and cofunded by the European Social Fund "Investing in your future". We acknowledge support from the Spanish Ministry of Science and Innovation through the "Centro de Excelencia Severo Ochoa 2019-2023" Program (2018-000806-S) and support from the Generalitat de Catalunya through the CERCA Program.

\section{Conflicts of Interest}

The authors declare that they have no conflict of interests.

\section{References}

1. Platts-Mills TAE. The allergy epidemics: 1870-2010. J Allergy Clin Immunol. 2015;136:3-13.

2. Asher MI, Montefort S, Björkstén B, Lai CK, Strachan DP, Weiland SK, et al. Worldwide time trends in the prevalence of symptoms of asthma, allergic rhinoconjunctivitis, and eczema in childhood: ISAAC Phases One and Three repeat multicountry cross-sectional surveys. Lancet. 2006;368:733-43.

3. Peters RL, Koplin JJ, Gurrin LC, Dharmage SC, Wake M, Ponsonby $A \mathrm{~L}$, et al. The prevalence of food allergy and other allergic diseases in early childhood in a populationbased study: HealthNuts age 4-year follow-up. J Allergy Clin Immunol. 2017; 140:145-53.e8.

4. Garcia-Aymerich J, Benet $M$, Saeys $Y$, Pinart M, Basagaña $X$, Smit HA, et al. Phenotyping asthma, rhinitis and eczema in MeDALL population-based birth cohorts: an allergic comorbidity cluster. Allergy. 2015;70:973-84.

5. Gupta RS, Warren CM, Smith BM, Blumenstock JA, Jiang J, Davis MM, et al. The Public Health Impact of Parent-Reported Childhood Food Allergies in the United States. Pediatrics. 2018;142:e20181235.

6. Prescott SL, Pawankar R, Allen KJ, Campbell DE, Sinn JKh, Fiocchi $A$, et al. A global survey of changing patterns of food allergy burden in children. World Allergy Organ J. 2013;6:21.

7. Vrijheid M, Slama R, Robinson O, Chatzi L, Coen M, van den Haze $P$, et al. The human early-life exposome (HELIX): project rationale and design. Environ Health Perspect. 2014;122:535-44

8. Beasley R, Semprini A, Mitchell EA. Risk factors for asthma: is prevention possible? Lancet. 2015;386:1075-85.

9. Winans B, Humble MC, Lawrence BP. Environmental toxicants and the developing immune system: a missing link in the global battle against infectious disease? Reprod Toxicol. 2011;31:327-36.

10. Barker DJ, Osmond C. Infant mortality, childhood nutrition, and ischaemic heart disease in England and Wales. Lancet. 1986;1:1077-81.

11. Bobolea I, Arismendi E, Valero A, Agustí A. Early Life Origins of Asthma: A Review of Potential Effectors. J Investig Allergol Clin Immunol. 2019;29:168-79.

12. Duijts L, Reiss IK, Brusselle G, de Jongste JC. Early origins of chronic obstructive lung diseases across the life course. Eur J Epidemiol. 2014;29:871-85.

13. Andersson NW, Hansen MV, Larsen AD, Hougaard KS, Kolstad HA, Schlünssen V. Prenatal maternal stress and atopic diseases in the child: a systematic review of observational human studies. Allergy. 2016;71:15-26.

14. Khreis H, Kelly C, Tate J, Parslow R, Lucas K, Nieuwenhuijsen $M$. Exposure to traffic-related air pollution and risk of development of childhood asthma: A systematic review and meta-analysis. Environ Int. 2017;100:1-31.

15. Achakulwisut P, Brauer M, Hystad P, Anenberg SC. Global, national, and urban burdens of paediatric asthma incidence attributable to ambient NO2 pollution: estimates from global datasets. Lancet Planet Heal. 2019;3:e166-78.

16. NowakK, JabłońskaE, Ratajczak-WronaW.Immunomodulatory effects of synthetic endocrine disrupting chemicals on the development and functions of human immune cells. Environ Int. 2019;125:350-64.

17. La Merrill MA, Vandenberg LN, Smith MT, Goodson W, Browne $P$, Patisaul HB et al. Consensus on the key characteristics of endocrine-disrupting chemicals as a basis for hazard identification. Nat Rev Endocrinol. 2020;16:45-57.

18. Eurostat. Chemicals production and consumption statistics. 2019. https://ec.europa.eu/eurostat/statistics-explained/index. 
php?title=Chemicals_production_and_consumption_statistics [Accessed 28April2020]

19. European Chemical Agency (ECHA). REACH substances Endocrine disruptor assessment list. 2020. https://echa. europa.eu/es/ed-assessment [Accessed 28April2020]

20. The Endocrine Disruption Exchange. TEDX List. 2018.https:// endocrinedisruption.org/interactive-tools/tedx-list-ofpotential-endocrine-disruptors/search-the-tedx-list [Accessed 28April2020]

21. Demeneix B, Slama R. European Parliament. Endocrine Disruptors: from Scientific Evidence to Human Health Protection. 2019.

22. European Commission DG Environment. Towards the establishment of a priority list of substances for further evaluation of their role in endocrine disruption. 2000.https:// ec.europa.eu/environment/chemicals/endocrine/strategy/ substances_en.htm [Accessed 28April2020]

23. Calafat AM, Ye X, Wong LY, Reidy JA, Needham LL. Exposure of the U.S. population to bisphenol A and 4-tertiary-octylphenol: 2003-2004. EnvironHealth Perspect. 2008;116:39-44.

24. Covaci A, Den Hond E, Geens T, Govarts E, Koppen G, Frederiksen $\mathrm{H}$, et al. Urinary BPA measurements in children and mothers from six European member states: Overall results and determinants of exposure. Environ Res. 2015;141:77-85.

25. Haug LS, Sakhi AK, Cequier E, Casas M, Maitre L, Basagana X, et al. In-utero and childhood chemical exposome in six European mother-child cohorts. Environ Int. 2018;121:751-63.

26. Dereumeaux C, Fillol C, Charles MA, Denys S. The French human biomonitoring program: First lessons from the perinatal component and future needs. Int J Hyg Environ Health. 2017;220:64-70.

27. Myridakis A, Fthenou E, Balaska E, Vakinti M, Kogevinas $M$, Stephanou EG. Phthalate esters, parabens and bisphenol-A exposure among mothers and their children in Greece (Rhea cohort). Environ Int. 2015;83:1-10.

28. European Commission. Study for the strategy for a non-toxic environment of the 7th Environment Action Programme. 2017. https://ec.europa.eu/environment/chemicals/non-toxic/ pdf/NTE main report final.pdf [Accessed 28April2020]

29. Trasande L, Zoeller RT, Hass U, Kortenkamp A, Grandjean P, Myers JP, et al. Burden of disease and costs of exposure to endocrine disrupting chemicals in the European Union: an updated analysis. Andrology. 2016;4:565-72.

30. Gascon M, Morales E, Sunyer J, Vrijheid M. Effects of persistent organic pollutants on the developing respiratory and immune systems: a systematic review. Environ Int. 2013;52:51-65.

31. Vrijheid $M$, Casas $M$, Gascon $M$, Valvi $D$, Nieuwenhuijsen $M$. Environmental pollutants and child health-A review of recent concerns. Int J Hyg Environ Health. 2016;219:331-42.

32. Net $S$, Sempéré $R$, Delmont A Paluselli $A$, Ouddane $B$. Occurrence, fate, behavior and ecotoxicological state of phthalates in different environmental matrices. Environ Sci Technol. 2015;49:4019-35.

33. Wormuth $M$, Scheringer $M$, Vollenweider M, Hungerbühler K. What are the sources of exposure to eight frequently used phthalic acid esters in Europeans? Risk Anal. 2006;26:80324.

34. European Chemicals Agency. Endocrine disrupting properties to be added for four phthalates in the Authorisation List. 2019. https://echa.europa.eu/es/-/endocrine-disrupting-propertiesto-be-added-for-four-phthalates-in-the-authorisation-list [Accessed 01May2020]

35. Christen V, Crettaz P, Oberli-Schrämmli A, Fent K. Some flame retardants and the antimicrobials triclosan and triclocarban enhance the androgenic activity in vitro. Chemosphere. 2010;81:1245-52.

36. Okubo T, Suzuki T, Yokoyama Y, Kano K, Kano I. Estimation of Estrogenic and Anti-estrogenic Activities of Some Phthalate Diesters and Monoesters by MCF-7 Cell Proliferation Assay in Vitro. Biol Pharm Bull. 2003;26:1219-24.

37. Grytting VS, Olderbø BP, Holme JA, Samuelsen JT, Solhaug A, Becher R. Di-n-butyl phthalate modifies PMA-induced macrophage differentiation of THP-1 monocytes via PPAR $\gamma$. Toxicol Vitr. 2019;54:168-77.

38. Fang H, Fang W, Cao H, Luo S, Cong J, Liu S, et al. Di-(2ethylhexyl)-phthalate induces apoptosis via the PPAR $\gamma /$ PTEN/ AKT pathway in differentiated human embryonic stem cells. Food Chem Toxicol. 2019;131:110552.

39. Miller MD, Marty MA. Impact of environmental chemicals on lung development. Environ Health Perspect. 2010;118:115564.

40. Bornehag CG, Nanberg E. Phthalate exposure and asthma in children. Int J Androl. 2010;33:333-45.

41. Kimber I, Dearman RJ. An assessment of the ability of phthalates to influence immune and allergic responses. Toxicology. 2010;271:73-82.

42. Li M-C, Chen C-H, Guo YL. Phthalate esters and childhood asthma: A systematic review and congener-specific metaanalysis. Environ Pollut. 2017;229:655-60.

43. Just AC, Whyatt RM, Perzanowski MS, Calafat AM, Perera FP, Goldstein IF, et al. Prenatal exposure to butylbenzyl phthalate and early eczema in an urban cohort. Environ Health Perspect. 2012;120:1475-80.

44. Whyatt RM, Perzanowski MS, Just AC, Rundle AG, Donohue $\mathrm{KM}$, Calafat AM, et al. Asthma in inner-city children at 5-11 years of age and prenatal exposure to phthalates: the Columbia Center for Children's Environmental Health Cohort. Environ Health Perspect. 2014;122:1141-6.

45. Gascon M, Casas M, Morales E, Valvi D, Ballesteros-Gómez A, Luque $N$, et al. Prenatal exposure to bisphenol $A$ and phthalates and childhood respiratory tract infections and allergy. J Allergy Clin Immunol. 2015;135:370-8.

46. Smit LA, Lenters $V$, Høyer BB, Lindh $\mathrm{CH}$, Pedersen $\mathrm{HS}$, Liermontova I, et al. Prenatal exposure to environmental chemical contaminants and asthma and eczema in school-age children. Allergy. 2015;70:653-60.

47. Ku HY, Su PH, Wen HJ, Sun HL, Wang CJ, Chen HY, et al. Prenatal and postnatal exposure to phthalate esters and asthma: a 9-year follow-up study of a Taiwanese birth cohort. PLoS One. 2015;10:e0123309.

48. Ashley-Martin J, Dodds L, Levy AR, Platt RW, Marshall JS, Arbuckle TE, et al. Prenatal exposure to phthalates, bisphenol A and perfluoroalkyl substances and cord blood levels of lgE, TSLP and IL-33. Environ Res. 2015;140:360-8.

49. Vernet C, Pin I, Giorgis-Allemand L, Philippat C, Benmerad M, Quentin J, et al. In Utero Exposure to Select Phenols and Phthalates and Respiratory Health in Five-Year-Old Boys: A Prospective Study. Environ Health Perspect. 2017;125:097006. 
50. Soomro MH, Baiz N, Philippat C, Vernet C, Siroux V, Nichole Maesano $C$, et al. Prenatal Exposure to Phthalates and the Development of Eczema Phenotypes in Male Children: Results from the EDEN Mother-Child Cohort Study. Environ Health Perspect. 2018;126:027002.

51. Buckley JP, Quirós-Alcalá L, Teitelbaum SL, Calafat AM, Wolff MS, Engel SM. Associations of prenatal environmental phenol and phthalate biomarkers with respiratory and allergic diseases among children aged 6 and 7 years. Environ Int. 2018;115:79-88.

52. Berger K, Eskenazi B, Balmes J, Holland N, Calafat AM, Harley KG. Associations between prenatal maternal urinary concentrations of personal care product chemical biomarkers and childhood respiratory and allergic outcomes in the CHAMACOS study. Environ Int. 2018;121:538-49.

53. Berger K, Eskenazi B, Balmes J, Kogut K, Holland N, Calafat $A M$, et al. Prenatal high molecular weight phthalates and bisphenol A, and childhood respiratory and allergic outcomes. Pediatr Allergy Immunol. 2019;30:36-46.

54. Podlecka D, Gromadzińska J, Mikołajewska K, Fijałkowska B, Stelmach I, Jerzynska J. Longitudinal effect of phthalates exposure on allergic diseases in children. Ann Allergy Asthma Immunol. 2020;125(1):84-9.

55. Stelmach I, Majak P, Jerzynska J, Podlecka D, Stelmach W, Polańska $K$, et al. The effect of prenatal exposure to phthalates on food allergy and early eczema in inner-city children. Allergy Asthma Proc. 2015:36:72-8.

56. INERIS (Institut National de I'Environnement Industriel et des Risques). Données technico-économiques sur les substances chimiques en France: substituts du DEHP. 2012. http:// www.ineris.fr/substances/fr/substance/getDocument/3231 [Accessed 28April2020].

57. Nagorka R, Koschorreck J. Trends for plasticizers in German freshwater environments - Evidence for the substitution of DEHP with emerging phthalate and non-phthalate alternatives. Environ Pollut. 2020;262:114237.

58. CHEMTrust - Protecting humans and wildlife from harmful chemicals. From BPA to BPZ: a toxic soup? 2018. https://www. chemtrust.org/wp-content/uploads/chemtrust-toxicsoupmar-18.pdf

59. European Commission. Directive 2011/8/EU of 26 January 2011 amending directive 2002/72/EC as regards the restriction of use of bisphenol $A$ in plastic infant feeding bottles. 2011.

60. European Chemical Agency (ECHA). Moving away from BPA in thermal paper. 2019.https://newsletter.echa.europa.eu/ home/-/newsletter/entry/moving-away-from-bpa-in-thermalpaper [Accessed 01May2020]

61. Rochester JR, Bolden AL. Bisphenol S and F: A Systematic Review and Comparison of the Hormonal Activity of Bisphenol A Substitutes. Environ Health Perspect. 2015;123:643-50.

62. Vandenberg $L N$, Hauser $R$, Marcus $M$, Olea N, Welshons WV. Human exposure to bisphenol A (BPA). Reprod Toxicol. 2007:24:139-77.

63. Kim JJ, Kumar S, Kumar V, Lee YM, Kim YS, Kumar V. Bisphenols as a Legacy Pollutant, and Their Effects on Organ Vulnerability. Int J Environ Res Public Health. 2019;17:112.

64. Rogers JA, Metz L, Yong WW. Review: Endocrine disrupting chemicals and immune responses: $A$ focus on bisphenol-A and its potential mechanisms. Mol Immunol. 2013;53:421-30.
65. Welshons WV, Nagel SC, vom Saal FS. Large effects from small exposures. III. Endocrine mechanisms mediating effects of bisphenol $A$ at levels of human exposure. Endocrinology. 2006; 147:S56-69.

66. Vandenberg LN, Maffini MV, Sonnenschein C, Rubin BS Soto AM. Bisphenol-A and the Great Divide: A Review of Controversies in the Field of Endocrine Disruption. Endocr Rev. 2009:30:75-95

67. Kwak ES, Just A, Whyatt R, Miller RL. Phthalates, Pesticides, and Bisphenol-A Exposure and the Development of Nonoccupational Asthma and Allergies: How Valid Are the Links? Open Allergy J. 2009;2:45-50.

68. Midoro-Horiuti T, Tiwari R, Watson CS, Goldblum RM Maternal bisphenol a exposure promotes the development of experimental asthma in mouse pups. Environ Health Perspect. 2010;118:273-7.

69. Clayton EM, Todd M, Dowd JB, Aiello AE. The Impact of Bisphenol A and Triclosan on Immune Parameters in the U.S. Population, NHANES 2003-2006. Environ Health Perspect. 2011;119:390-6.

70. Luo S, Li Y, Li Y, Zhu Q, Jiang J, Wu C, et al. Gestational and lactational exposure to low-dose bisphenol A increases Th17 cells in mice offspring. Environ Toxicol Pharmacol. 2016;47:149-58.

71. Konkel L. BPA and Altered Airway Cells: Association Seen in Rhesus Macaques after Third-Trimester Exposure. Environ Health Perspect. 2013;121:A254.

72. Mendy A, Salo PM, Wilkerson J, Feinstein L, Ferguson KK, Fessler MB. Association of urinary levels of bisphenols $F$ and $\mathrm{S}$ used as bisphenol A substitutes with asthma and hay fever outcomes. Environ Res. 2020;183:108944.

73. Xie MY, Ni H, Zhao DS, Wen LY, Li KS, Yang HH, et al. Exposure to bisphenol $A$ and the development of asthma: A systematic review of cohort studies. Reprod Toxicol. 2016;65:224-9.

74. Spanier AJ, Kahn RS, Kunselman AR, Hornung $R$, $X u Y$, Calafat AM, et al. Prenatal exposure to bisphenol $A$ and child wheeze from birth to 3 years of age. Environ Health Perspect. 2012;120:916-20.

75. Zugna D, Galassi C, Annesi-Maesano I, Baïz N, Barros H, Basterrechea $\mathrm{M}$, et al. Maternal complications in pregnancy and wheezing in early childhood: a pooled analysis of 14 birth cohorts. Int J Epidemiol. 2015;44:199-208.

76. Spanier AJ, Kahn RS, Kunselman AR, Schaefer EW, Hornung $R, X u Y$, et al. Bisphenol a exposure and the development of wheeze and lung function in children through age 5 years. JAMA Pediatr. 2014;168:1131-7.

77. Donohue KM, Miller RL, Perzanowski MS, Just AC, Hoepner LA, Arunajadai $S$, et al. Prenatal and postnatal bisphenol $A$ exposure and asthma development among inner-city children. J Allergy Clin Immunol. 2013;131:736-42.

78. Zhou A, Chang H, Huo W, Zhang B, Hu J, Xia W, et al. Prenatal exposure to bisphenol $A$ and risk of allergic diseases in early life. Pediatr Res. 2017:81:851-6.

79. Castelain F, Castelain M. Parabens: a real hazard or a scare story? Eur J Dermatol. 2012;22:723-7.

80. European Commission. Consumers: Commission improves safety of cosmetics. 2014.https://ec.europa.eu/ commission/presscorner/detail/en/IP_14_1051 [Accessed 28April2020] 
81. Jackson-Browne MS, Henderson N, Patti M, Spanier A, Braun JM. The Impact of Early-Life Exposure to Antimicrobials on Asthma and Eczema Risk in Children. Curr Environ Heal Reports. 2019;6:214-24.

82. Savage JH, Matsui EC, Wood RA, Keet CA. Urinary levels of triclosan and parabens are associated with aeroallergen and food sensitization. J Allergy Clin Immunol. 2012;130:453-60.

83. Soni MG, Taylor SL, Greenberg NA, Burdock GA. Evaluation of the health aspects of methyl paraben: a review of the published literature. Food Chem Toxicol. 2002;40:1335-73.

84. Lee-Sarwar K, Hauser R, Calafat AM, Ye X, O'Connor GT, Sandel $M$, et al. Prenatal and Early Life Triclosan and Parabens Exposure and Allergic Outcomes. J Allergy Clin Immunol. 2018 Jul;142(1):269-78.e15.

85. Dann AB, Hontela A. Triclosan: environmental exposure, toxicity and mechanisms of action. J Appl Toxicol 2011;31:285-311.

86. Ashley-Martin J, Dodds L, Arbuckle TE, Marshall J. Prenatal triclosan exposure and cord blood immune system biomarkers. Int J Hyg Environ Health. 2016;219:454-7.

87. Kim S, Choi K. Occurrences, toxicities, and ecological risks of benzophenone-3, a common component of organic sunscreen products: a mini-review. Environ Int. 2014;70:143-57.

88. European Commission. Commission regulation (EU) 2017/238 - amending Annex VI to Regulation (EC) No 1223/2009 of the European Parliament and of the Council on cosmetic products. 2017. https://eur-lex.europa.eu/legal-content/ EN/TXT/PDF/?uri=CELEX:32017R0238\&rid=7 [Accessed 28April2020]

89. European Commission. EURION - European Cluster to Improve Identification of Endocrine Disruptors. 2020.https:// eurion-cluster.eu/ [Accessed 28April2020]

90. Welshons WV, Thayer KA, Judy BM, Taylor JA, Curran EM, vom Saal FS. Large effects from small exposures. I. Mechanisms for endocrine-disrupting chemicals with estrogenic activity. Environ Health Perspect. 2003;111:994-1006.

91. Gascon M, Sunyer J, Casas M, Martínez D, Ballester $F$, Basterrechea M, et al. Prenatal exposure to DDE and PCB 153 and respiratory health in early childhood: a meta-analysis. Epidemiology. 2014;25:544-53.

92. Casas $M$, Nieuwenhuijsen $M$, Martínez $D$, Ballester $F$, Basagaña $X$, Basterrechea $M$, et al. Prenatal exposure to PCB153, p,p'-DDE and birth outcomes in 9000 mother-child pairs: exposure-response relationship and effect modifiers. Environ Int. 2015;74:23-31.

93. Dekant $W$, Volkel $W$. Human exposure to bisphenol $A$ by biomonitoring: methods, results and assessment of environmental exposures. Toxicol Appl Pharmacol. 2008;228:114-34.

94. Pollack AZ, Perkins NJ, Mumford SL, Ye A, Schisterman EF. Correlated biomarker measurement error: an important threat to inference in environmental epidemiology. Am J Epidemiol. 2013;177:84-92.

95. Perrier F, Giorgis-Allemand L, Slama R, Philippat C. Withinsubject Pooling of Biological Samples to Reduce Exposure Misclassification in Biomarker-based Studies. Epidemiology. 2016;27:378-88.

96. Casas M, Basagaña X, Sakhi AK, Haug LS, Philippat C, Granum $B$, et al. Variability of urinary concentrations of non-persistent chemicals in pregnant women and school-aged children. Environ Int. 2018;121:561-73.
97. Béranger $R$, Hardy EM, Dexet $C$, Guldner $L$, Zaros $C$, Nougadère $A$, et al. Multiple pesticide analysis in hair samples of pregnant French women: Results from the ELFE national birth cohort. Environ Int. 2018;120:43-53.

98. O'Connell SG, Kincl LD, Anderson KA. Silicone Wristbands as Personal Passive Samplers. Environ Sci Technol. 2014;48:332735.

99. Dixon HM, Scott RP, Holmes D, Calero L, Kincl LD, Waters KM, et al. Silicone wristbands compared with traditional polycyclic aromatic hydrocarbon exposure assessment methods. Anal Bioanal Chem. 2018;410:3059-71.

100. Hohmann C, Pinart M, Tischer C, Gehring U, Heinrich J, Kull I, et al. The development of the MeDALL Core Questionnaires for a harmonized follow-up assessment of eleven European birth cohorts on asthma and allergies. Int Arch Allergy Immunol. 2014;163:215-24.

101. Savenije OE, Granell R, Caudri D, Koppelman GH, Smit HA, Wijga A, et al. Comparison of childhood wheezing phenotypes in 2 birth cohorts: ALSPAC and PIAMA. J Allergy Clin Immunol. 2011;127:1505-12.e14.

102. Belgrave DCM, Granell R, Turner SW, Curtin JA, Buchan IE, Le Souëf PN, et al. Lung function trajectories from pre-school age to adulthood and their associations with early life factors: a retrospective analysis of three population-based birth cohort studies. Lancet Respir Med. 2018;6:526-34.

103. Kankaanranta $H$, Kauppi $P$, Tuomisto LE, Ilmarinen P. Emerging Comorbidities in Adult Asthma: Risks, Clinical Associations, and Mechanisms. Mediators Inflamm. 2016;2016:1-23.

104. Cortese S, Sun S, Zhang J, Sharma E, Chang Z, Kuja-Halkola $R$, et al. Association between attention deficit hyperactivity disorder and asthma: a systematic review and meta-analysis and a Swedish population-based study. Lancet Psychiatry. 2018;5:717-26.

105. Stafoggia M, Breitner S, Hampel R, Basagaña X. Statistical Approaches to Address Multi-Pollutant Mixtures and Multiple Exposures: the State of the Science. Curr Environ Heal reports. 2017:4:481-90.

106. Lazarevic N, Barnett AG, Sly PD, Knibbs LD. Statistical Methodology in Studies of Prenatal Exposure to Mixtures of Endocrine-Disrupting Chemicals: A Review of Existing Approaches and New Alternatives. Environ Health Perspect. 2019;127:26001.

107. Ribeiro E, Ladeira C, Viegas S. EDCs Mixtures: A Stealthy Hazard for Human Health? Toxics. 2017;5(1):5.

108. Kortenkamp A, Faust M. Regulate to reduce chemical mixture risk. Science. 2018;361:224-6.

109. Whyatt RM, Rundle AG, Perzanowski MS, Just AC, Donohue KM, Calafat AM, et al. Prenatal phthalate and early childhood bisphenol A exposures increase asthma risk in inner-city children. J Allergy Clin Immunol. 2014;134:1195-7.e2.

110. Goodson WH, Lowe L, Carpenter DO, Gilbertson M, Manaf Ali A, Lopez de Cerain Salsamendi A, et al. Assessing the carcinogenic potential of low-dose exposures to chemical mixtures in the environment: the challenge ahead. Carcinogenesis. 2015;36 Suppl 1:S254-96.

111. Santos S, Maitre L, Warembourg C, Agier L, Richiardi L, Basagaña $X$, et al. Applying the exposome concept in birth cohort research: a review of statistical approaches. Eur J Epidemiol. 2020;35:193-204. 
112. Meek ME, Boobis AR, Crofton KM, Heinemeyer G, Raaij MV, Vickers C. Risk assessment of combined exposure to multiple chemicals: A WHO/IPCS framework. Regul Toxicol Pharmacol. 2011;60:S1-14.

113. Yang CF, Karmaus WJJ, Yang CC, Chen ML, Wang IJ. Bisphenol a Exposure, DNA Methylation, and Asthma in Children. Int J Environ Res Public Health. 2020;17:298.

114. Wang IJ, Karmaus WJ, Chen SL, Holloway JW, Ewart S. Effects of phthalate exposure on asthma may be mediated through alterations in DNA methylation. Clin Epigenetics. 2015;7:27.

115. Felix JF, Joubert BR, Baccarelli AA, Sharp GC, Almqvist C, Annesi-Maesano I, et al. Cohort Profile: Pregnancy And Childhood Epigenetics (PACE) Consortium. Int J Epidemiol. 2018;47:22-23u.

116. Claus SP, Guillou H, Ellero-Simatos S. The gut microbiota: a major player in the toxicity of environmental pollutants? NPJ Biofilms Microbiomes. 2016;2:16003.
117. Malaisé Y, Ménard S, Cartier C, Lencina C, Sommer C, Gaultier $E$, et al. Consequences of bisphenol a perinatal exposure on immune responses and gut barrier function in mice. Arch Toxicol. 2018;92:347-58.

118. Rosenfeld CS. Gut Dysbiosis in Animals Due to Environmental Chemical Exposures. Front Cell Infect Microbiol. 2017;7:396.

Manuscript received May 1, 2020; accepted for publication May 11, 2020.

\section{Maribel Casas}

E-mail: maribel.casas@isglobal.org 